\title{
The Relationship Between Online Gamification Performance Score With Body Mass Index Of Overweight Nursing Students During Covid-19 Pandemic
}

\author{
Jocelyn B. Hipona*1, Alicia Tuazon ${ }^{1}$, Joan Martin'1, Marlyn Lumitap Cabading ${ }^{2}$ \\ ${ }^{1}$ La Consolacion University of the Philippines, Malolos, Bulacan, Philippines \\ ${ }^{2}$ Our Lady of Fatima University, Valenzuela City, Philippines \\ Corresponding author: jocelyn.hipona@email.lcup.edu.ph
}

\begin{abstract}
Background: Online intervention platforms are effective for gathering data especially in this pandemic crisis we are currently experiencing, and it can help healthcare practitioners on future innovations. Numerous studies also show the importance of online nursing intervention platforms in the promotion of health on overweight and obese adults, by way of social media.
\end{abstract}

Purpose: This study aimed to determine relationship between online gamification performance score with body mass index of overweight nursing students during covid-19 pandemic.

Methods: The total number of participants were 60 based on the type of research employed, computation of BMI and proper assessment before the study was conducted to make sure that participants meet the inclusion criteria.

Results: Evidence from this study illustrates that the performance assessment score in online gamification has almost no relationship with changes in the body mass index.

Conclusion: There are no changes in the body mass index of the overweight nursing students whether exposed to usual daily activities or online gamification. Data indicates that the four (4) week intervention to online gamification does not have relational changes on body mass index.

Keywords: Online Gamification Performance Score, Overweight Nursing Students, Body Mass Index. 
Journal Of Nursing Practice

http://thejnp.org

ISSN: 2614-3488 (print); 2614-3496 (online)

Vol.5 No.1. October 2021. Page.6-11

\section{BACKGROUND}

During the COVID-19 pandemic while there are no festivities, yet people are staying at home and many of them have stocked up on food. The pandemic with its uncertainty is also causing emotional distress. Emotional distress is associated with the liberation of cortisol from the adrenal cortex which is activated by the corticotropin releasing hormone $(\mathrm{CRH})$ liberated by the hypothalamus and subsequent activation of the pituitary gland. Cortisol, a glucocorticoid hormone, is responsible for regulating glucose metabolism and can lead to appetite stimulation, desire to consume fatty foods, sugary foods which can lead to weight gain. Prolonged stay at home can lead to the isolation effect on the parasympathetic nervous system and sustained release of cortisol leading to weight gain. Hence, the triad of abundant availability of food, staying at home, and emotional distress has the potential to cause weight gain among both adults and children. This problem is also compounded by lack of or decreased physical activity and altered sleep time both of which are important contributors to weight gain.

The diet of most college students is typically lacking in fruit, vegetable, and dairy consumption but is high in fat, sodium, and sugar. College students also have limited food variety, high snacking frequency, high incidence of meal skipping for weight loss, and a high consumption of fast foods. Poor consumption of fruit, vegetables, and dairy products, diets lacking in nutrient quality, and sporadic meal patterns increase nutritional risk and unwanted weight gain. The diets of college students tend to be high in fat, saturated fat, cholesterol, and sodium while they are low in fiber; vitamins A,C, and E; folate; iron; and calcium. Some students also receive little allowance, this may cause them to buy highcalorie processed foods such as fast foods because they typically cost less than healthier foods. Poor eating habits is a major public health concern among young adults who experience transition into university life during which they are exposed to stress and lack of time (El-Kassas et al., 2015).

Researchers and clinicians have capitalized on the use of technologies, such as the Internet and mobile devices (eg, PDAs, smartphones, cellular phones), to deliver weight management interventions. Such platforms are attractive because they help overcome resource and access barriers encountered when delivering traditional face-to-face individual or group interventions. Consequently, these platforms may enhance our ability to produce significant and healthy change in larger segments of the overweight and obese population. The World Health Organization has also recognized the importance of social resources as a valuable agent for behavior change in health promotion. According to the Ottawa Charter for Health Promotion, in addition to access to health information and services, individuals also need the online interventions or social resources to support healthful life practices. With the nature of interpersonal interactions evolving in line with advancing digital technology, interactive online platforms such as social media may prove to be an effective method of engaging social resources for health promotion interventions. Health Care Professionals or HCPs can use social media to potentially improve health outcomes, develop a professional network, increase personal awareness of news and discoveries, motivate patients, and provide health information to the community.

It is essential to enable, develop and promote innovative educational programs which increase the number of trained health providers, whilst ensuring that the quality and relevance of training meets these new challenges (WHO 2011). The increased use of information and communication technologies is recognized as one of the key strategic platforms on which to build strong education and training systems. Innovative ways of teaching and learning are required to respond to the need for health professional education, tackle the shortage of trained healthcare workers and ultimately improve patient care. 


\section{Journal Of Nursing Practice}

http://thejnp.org

ISSN: 2614-3488 (print); 2614-3496 (online)

Vol.5 No.1. October 2021. Page.6-11

eLearning may be one such innovation.

Gamification transposes game mechanisms and elements to non-game contexts as a way to motivate people, initiate participating processes and improve user experiences (Deterding et al., 2011). Badges, rewards or social competitions are thereby employed to orient and positively influence individuals' motivation, behaviour and/or productivity (Deterding et al., 2011; Huotari and Hamari, 2012; Blohm and Leimeister, 2013).

Evidence suggests that gamification increases enjoyment, engagement and compliance of health-related activities, while positively impacting health outcomes and cost of service delivery (Lenihan, 2012; Pereira et al., 2014). Its implementation is reinforced by the development of advanced digital health platforms, built around ecosystems of wearable and mobile devices, such as fitness trackers or other sensing devices like smartphones (Thiebes et al., 2014; Rapp, 2017). Whether these digital services are conceived to enhance individuals' well-being, guide rehabilitation periods or assist patients in their disease management, gamification holds great potential for adding further positive experiences to their primary health-related goals (Alahäivälä and Oinas-Kukkonen, 2016; Sardi et al., 2017).

According to previous studies, online intervention platforms are effective for gathering data especially in this pandemic crisis we are currently experiencing and it can help healthcare practitioners on future innovations. Numerous studies also show the importance of online nursing intervention platforms in the promotion of health on overweight and obese adults, by way of social media. There are various factors that contributed to the problem of sudden weight gain among college students such as improper self-care habits, food choices and lack of physical activity and sleep which were also discussed. Based on previous studies, gamification has a positive impact in health and wellbeing, especially in health behaviors through this platform it can help motivate individuals by way of point scores, badges, challenges and rankings to achieve the main goal.

\section{METHODS}

\section{Research Design}

The researchers employed descriptive research design in gathering the necessary information in the study. A nonequivalent control group pretest-posttest design, which involves experimental treatment and two groups of subjects observed before and after its implementation, in order to achieve the expected outcome which is to have reduction with the respondents' BMI, the data was collected from October to November among nursing students who met the inclusion criteria. The researchers utilized the counterbalance Latin square experimental design. This is one of the best ways to avoid the pitfalls of standard repeated measures where the subjects are exposed to all the treatments.

\section{Respondents of the Study}

This research includes the Bachelor of Science in Nursing (BSN) $2^{\text {nd }}$ year level and BSN 3rd year level at a University which was granted an autonomous status by the Commission on Higher Education (CHED) in Manila from Institute of Nursing of AY 20202021 who were within the range of overweight with reference to BMI were selected for the research. The total number of participants were 60 based on the type of research employed, the participants was divided into 2 groups, the control and experimental group. The initial number of participants was 30 for each group, participants were selected from the Institute of Nursing. Computation of BMI and proper assessment before the study was conducted to make sure that participants meet the inclusion criteria. 


\section{Research Instrument}

The study utilized four tools to gather pertinent data for the respondents. The first tool is a self-made demographic questionnaire tool, which was utilized to obtain baseline information from the participants. This tool assisted the researchers to classify and obtain necessary information that were pertinent to the study. The second tool that was utilized is a digital weighing scale. In order for the participants to measure correctly and acquire accurate results, the digital weighing scale must be well-calibrated before use or measurement on a flat surface where the tool was used. The third tool is a tape measure to measure height of each participant. Height and weight were measured twice through Google Meet or Zoom to ascertain accurate and correct measurement. The last tool is the Online Platform. The objective of the online platform is to provide a solution that can disseminate information and health education rapidly to a number of participants in a way that it was convenient and accessible to them. Online Gamification was applied with the online platform to be able to motivate and encourage participation of the students. It contains health education and physical exercise that the participants were accomplished for 45 days through online platforms. The online platforms that was used include Google Meet, Google Classroom, and Zoom in order to monitor the participants' progress. Google Meet was used to monitor their activities such as online zumba, cardio and strength exercises. Google Classroom was used for health teaching and post-assessments. Zoom was used as an alternative for the monitoring of exercises. Facebook Messenger were utilized as a communication platform.

\section{Statistical Treatment of Data}

Frequency and percentage, was used to processed the data in relation to the profile of the respondents in terms of age, gender, year level, level of knowledgeability and the performance assessment score. Independent t-test was used to determine significant difference in the evaluation of the body mass index during the pre-experimental and postexperimental both using the online gamification as well as the usual daily activities of the participants. Pearson R Product Coefficient was used to determine the significant relationship between the performance score assessment on the online gamification and the body mass index of the participants. This research opted to determine the $95 \%$ validity of the study with a $5 \%$ degree of error and set at P-values of $<0.05$ was assumed to be statistically significant.

\section{Ethical Consideration}

Ethical guidelines were followed for the whole research period. The researcher submitted the study for review and approval of the Ethics Review Board of the university. It followed the National Ethical Guidelines for Health and Health-Related Research 2017 prepared by the Philippine Health Research Ethics Board.

\section{RESULTS}

The frequency and percentage distribution of the demographic profile of the respondents based on age, sex, year level and body mass index. Majority of the participants belong to ages 20 years old which were mostly female for both the experimental and the control group. Data shows that course like Bachelor of Science in Nursing is a female dominated career being more compassionate and have a more caring ability than male. In addition, majority of the participants are in early adulthood stage of life, a period of rapid personal development of an individual's experiences having major life transitions. 
Table 1. Significant difference in the Body Mass Index of the overweight nursing students between online gamification group and usual daily activities

\begin{tabular}{llllll}
\hline t- test & df & $\begin{array}{l}\text { Significant } \\
\text { value }\end{array}$ & p-value & Interpretation & Decision \\
\hline-1.34 & 39 & 0.188 & 0.05 & $\begin{array}{l}\text { No Significant } \\
\text { Difference }\end{array}$ & $\begin{array}{l}\text { Do not Accept the } \\
\text { Null Hypothesis }\end{array}$ \\
\hline
\end{tabular}

The significant difference in the body mass index of the participants between those subjected to online gamification and those exposed to uninterrupted usual daily activities using unparallel t-test. It can be depicted from the table that the body mass index before and after was able to garner a t- value of -1.34 with 39 degree of freedom with significant $p$-value of 0.188 that is significantly higher than the cut off $p$-value of 0.05 . Hence the null hypothesis will be accepted, Therefore, there is no significant difference in the body mass index in the control group that were subjected to usual daily activities and experimental group that were subjected to online gamification after four (4) weeks of intervention.

This indicates that no changes in the body mass index of the overweight nursing students whether exposed to usual daily activities or online gamification. It can also be noted on the mean score difference of 0.67 in table 3 that signified changes in BMI but it could not be concluded to reach the significant changes. This can be attributed to limited time of exposure to 4 weeks in online gamification wherein change can be seen in little values. Also, the unforeseen circumstances such as the typhoon which was happened during the time of data collection and weak internet connections that interrupted the activities of the participants to online gamification.

Table 2. Significant relationship between the level of performance in the online gamification and the body mass index of overweight nursing students using Pearson $R$ Correlation Analysis

\begin{tabular}{lllll} 
R-value & $\mathrm{R}^{2}$ - value & $\mathrm{p}$-value & Interpretation & Decision \\
0.466 & 0.190 & 0.05 & $\begin{array}{l}\text { No Significant } \\
\text { relationship }\end{array}$ & $\begin{array}{l}\text { Do not Accept the } \\
\text { Null Hypothesis }\end{array}$ \\
\hline
\end{tabular}

It can be gleaned from the table that the significant $\mathrm{R}$-value of 0.466 is significantly higher than the cut off $\mathrm{p}$-value of 0.05 . Hence the null hypothesis will be accepted. Thus, there is no significant relationship between the online gamification performance scores with the body mass index. Data indicates that the four (4) week intervention to online gamification does not have a relational change on body mass index.

Based on the table of strength of relationship in Pearson's $\mathrm{R}$ correlation the computed $\mathrm{R}^{2}$ value is 0.1910 will fall under the "Very Low Correlation" where R value is between 0.19 and below. This indicates that the performance assessment score in online gamification has almost no relationship with changes in the body mass index.

\section{CONCLUSION}

The significant difference in the body mass index of the participants between those subjected to online gamification and those exposed to uninterrupted usual daily activities using unparallel t-test has no significant difference in the body mass index in the control group that were subjected to usual daily activities and experimental group that were subjected to online gamification after four (4) weeks of intervention. There are no changes in the body mass index of the overweight nursing students whether exposed to usual daily activities or 


\section{Journal Of Nursing Practice}

http://thejnp.org

ISSN: 2614-3488 (print); 2614-3496 (online)

Vol.5 No.1. October 2021. Page.6-11

online gamification. Data indicates that the four (4) week intervention to online gamification does not have relational changes on body mass index. The strength of relationship in Pearson's R correlation the computed $\mathrm{R}^{2}$ value under the "Very Low Correlation" indicates that the performance assessment score in online gamification has almost no relationship with changes in the body mass index.

\section{CONFLICTS OF INTEREST DISCLOSURE}

The authors declare there are no significant competing financial, professional, or personal interests that might have influenced the performance or presentation of the work described in this manuscript.

\section{ACKNOWLEDGEMENT}

The authors would like to extend their sincere gratitude and deepest appreciation to their affiliations and to the participants that led to the possible accomplishment of this research work.

\section{REFERENCES}

Beck, C. T., \& Polit, D. E. (2004). Nursing Research: Principles and Methods (7th edition). Lippincott-Raven.

Lazarou, C., \& Kouta, C. (2010). The role of nurses in the prevention and management of obesity. British journal of nursing (Mark Allen Publishing), 19(10), 641-647. https://doi.org/10.12968/bjon.2010.19.10.48203

Marston, H., \& Hall, A. (2015) Gamification: Applications for health promotion and health information technology engagement. Retrieved June 4, 2020, from https://www.researchgate.net/publication/298083668_Gamification_Applications f or health promotion and health information technology engagement

Potter, P. A., Perry, A. G., Hall, A., \& Stockert, P. A. (2015). Fundamentals of nursing.

Sharma M. Potential of weight gain during COVID-19 community-wide quarantine. Adv Obes Weight Manag Control. 2020;10(2):48-49. DOI: 10.15406/aowmc.2020.10.00305

Templin, T., Hashiguchi, T. C. O., Thomson, B., Dieleman, J., \& Bendavid, E. (2019). The overweight and obesity transition from the wealthy to the poor in low- and middleincome countries: A survey of household data from 103 countries. PLOS Medicine, 16(11). doi: 10.1371/journal.pmed.1002968

Urbanetto, J. S., Rocha, P., Dutra, R. C., Maciel, M. C., Bandeira, A. G., \& Magnago, T. (2019). Stress and overweight/obesity among nursing students. Estresse e sobrepeso/obesidade em estudantes de enfermagem. Revista latino-americana de enfermagem, 27, e3177. https://doi.org/10.1590/1518-8345.2966.3177

Ventola C. L. (2014). Social media and health care professionals: benefits, risks, and best practices. P \& T : a peer-reviewed journal for formulary management, 39(7), 491520.

World Health Organization - WHO. Global action plan for the prevention and control of noncommunicable diseases 2013-2020. Geneva (SWI): World Health Organization; 2013[Cited 2016 aug 08]. http://apps.who.int/iris/bitstream/10665/94384/1/9789241506236_eng.pdf 